\title{
FTIR, XRD, SEM, TGA Investigations of Ammonium Dihydrogen Phosphate (ADP) Single Crystal
}

\author{
A. Jegatheesan \\ Department of Physics \\ Paavaai Group of Institutions \\ Namakkal \\ TamilNadu, India. \\ J. Murugan \\ Department of Physics \\ Sree Krishna College of Engg \\ Vellore \\ TamilNadu, India
}

\author{
B. Neelakantaprasad \\ Department of Physics \\ KSR College of Engg \\ Tiruchengode \\ TamilNadu, India \\ G. Rajarajan \\ Department of Physics \\ Mahendra Engg. College \\ Namakkal \\ TamilNadu, India.
}

\begin{abstract}
Ammonium dihydrogen Phosphate (ADP), crystals are good Second Harmonic Generators (SHG) having appreciable Non Linear Optical properties. Single crystals of ammonium dihydrogen phosphate were grown using slow evaporation technique at $30^{\circ} \mathrm{C}$. In order to study of ADP, X-ray diffraction studies were carried out on the crystals using Bruker AXS D8 Advance X-ray diffractometer with $\mathrm{Cu} \mathrm{K \alpha}$ radiation. The grown single crystals have been analyzed with FT-IR, TGA measurements. Some novel results of a combined sequential study of growth spirals on the basal surface of the richly polytypic ADP crystals by scanning electron microscopy (SEM) is presented and discussed.
\end{abstract}

\section{Keywords}

Crystal growth, Solution growth technique, XRD, FTIR, SEM, TGA

\section{INTRODUCTION}

Ammonium dihydrogen phosphate (ADP), or monoammonium phosphate, $\left(\mathrm{NH}_{4} \mathrm{H}_{2} \mathrm{PO}_{4}\right)$, is formed when a solution of phosphoric acid is added to ammonia until the solution is distinctly acidic. It crystallizes in quadratic prisms. Monoammonium phosphate is often used in the blending of dry agricultural fertilizers. It supplies soil with the elements nitrogen and phosphorus in a form which is usable by plants. Currently, $\mathrm{KH}_{2} \mathrm{PO}_{4}$ (KDP) and $\mathrm{NH}_{4} \mathrm{H}_{2} \mathrm{PO}_{4}$ (ADP) are the available nonlinear crystals needed for laser radiation conversion in laser fusion system. Laser fusion research needs large plates of nonlinear crystals for electro-optic switches and frequency converters. The properties of potassium dihydrogen orthophosphate (KDP) and its analogs include transparency in a wide region of the optical spectrum, resistance to damage by laser radiation and relatively high nonlinear efficiency, in combination with reproducible growth to large size and easy finishing ${ }^{[1]}$.

XRD studies were carried out with the grown crystals in powdered form. The powder samples were loaded into Bruker AXS D8 Advance X-ray diffractometer with $\mathrm{Cu} \mathrm{K} \alpha$ radiation $(\lambda=1.5417)$ with an applied operating voltage $40 \mathrm{kV}$ and current $35 \mathrm{~mA}$. Scanning rate was maintained at $18 \mathrm{~min}^{-1}$ over a $2 \theta$ range of $10-80^{\circ}$, employing the reflection mode for scanning. From this measurement we found the lattice
Studies on Ammonium dihydrogen Phosphate (ADP) crystals still attract interest because of their unique non-linear optical, dielectric and antiferroelectric properties and their varied uses as electro-optic modulator, harmonic generators and parametric generator. They are still widely used as nonlinear optical devices and the choicest electro - optic materials having wide practical application ${ }^{[2-13]}$. Several researchers have carried out a lot of studies on pure ADP crystals ${ }^{[14-16]}$. Studies have also been made about the effect of mixing of divalent and trivalent impurities on the growth, habit modification and structure of ADP ${ }^{[17-20]}$.In this research article, we have presented some aspects on the growth and Xray diffraction characteristics of ADP single crystal.

\section{EXPERIMENTAL DETAILS}

\subsection{Crystal Growth}

Crystal growth of pure ADP was done by Solution growth technique at room temperature. Analytical grade ADP had been re-crystallized thrice to extract pure ADP. Saturated ADP solution was prepared using water as solvent. Equal amount of ADP solution was poured into beakers. ADP solution were thoroughly mixed, stirred, filtered and poured into five patria dishes and kept for evaporation at $30{ }^{\circ} \mathrm{C}$. Within 6-8 days tiny crystals appeared in patria dishes. However, ADP crystals appeared last ( 8 days) in the patria dish. All crystals reached a maximum size in 12 days.

\section{CHARACTERIZATION ANALYSIS}

The grown single crystal of ADP was subjected to different characterization studies such as powder $\mathrm{X}$ - ray diffraction, FT-IR and Thermal stability of the sample was tested using DTA and thermo gravimetric analysis (TGA) . Some novel results of a combined sequential study of growth spirals on the basal surface of the richly polytypic ADP crystals by scanning electron microscopy (SEM) is presented and discussed.

\subsection{X-ray Diffraction Analysis:}

dimensions as: $a=b=7.5006^{\circ}, c=7.5490 \mathrm{~A}^{\circ}, \alpha=\beta=\gamma=90^{\circ}$ having space group I $42 d d$ and the lattice parameters are in good agreement with the reported values. XRD values of ADP crystallites are in good agreement with standard JCPDS card No. 850815. There are no other phases that were observed beside the tetragonal system. The prominent peaks in the XRD pattern have been indexed as shown in Fig.1. The 
differences in the peak amplitude can be attributed to the different sizes and orientation of the powdered grains

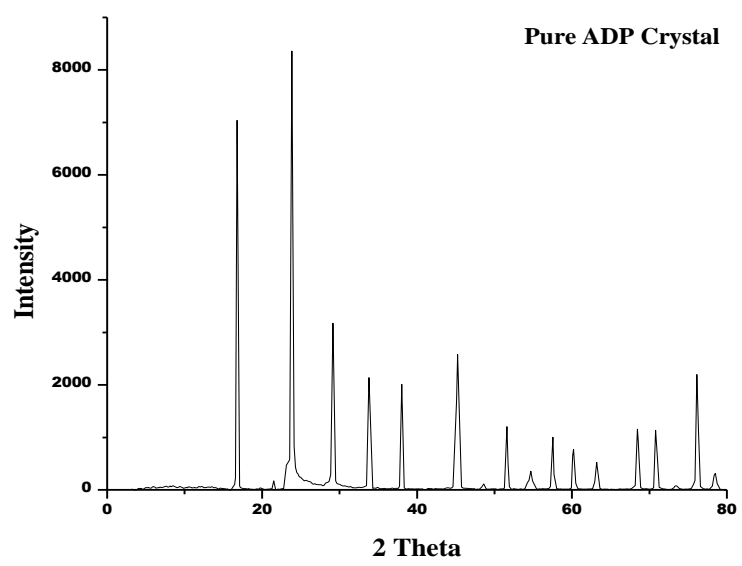

Fig 1: XRD spectra of Pure ADP

\subsection{Fourier Transforms Infrared (FT-IR) Analysis:}

The Fourier Transform Infra Red (FTIR) investigations were also carried out on the powdered samples of ADP. The spectrum was observed from Thermo Nicolet, Avatar 370 sectrophotometer in the region 400 to $4000 \mathrm{~cm}^{-1}$ using $\mathrm{KBr}$ pellet. The prominent peaks in the FTIR pattern have been indexed as shown in Fig. 2. Many useful observations were observed. The group frequency region was located between $4000 \mathrm{~cm}^{-1}$ to $1300 \mathrm{~cm}^{-1}$ and the fingerprint region 1300 to 630 $\mathrm{cm}^{-1}$. The intermediate frequency range 2500 to $1540 \mathrm{~cm}^{-1}$ (unsaturated region) contains triple bond frequencies which appear from 2500 to $2000 \mathrm{~cm}^{-1}$ and double bond frequencies from 2000 to $1540 \mathrm{~cm}^{-1}$. In the region between 1300 to 650 $\mathrm{cm}^{-1}$ there are single bond stretching frequencies and bending vibration of polyatomic systems involving motions of bonds linking a substituent group to the molecule. In the spectrum of $\mathrm{ADP}$, there is a broadband in the higher energy region due to $\mathrm{O}-\mathrm{H}$ stretching vibration of ADP and water. Hydrogen bonding within the crystal is suggested to be the cause for broadening. Presence of water is supported by its bending vibrations occurring at the band $1642.93 \mathrm{~cm}^{-1}{ }^{[21]}$. The bands below $1300 \mathrm{~cm}^{-1}$ is duetoPO $\mathrm{PO}_{4}$ vibrations. It includes the $\mathrm{OH}$ stretch of hydrogen bonded carboxyl groups, the asymmetric stretching mode of $\mathrm{NH}^{3+}$ at $3249.11 \mathrm{~cm}^{-1}$ and $\mathrm{CH}_{2}$ stretching mode just below $3000 \mathrm{~cm}^{-1}$. The absorption at $1642.93 \mathrm{~cm}^{-1}$ is assigned to $\mathrm{C}=\mathrm{O}$ stretching of $-\mathrm{COOH}$ group. The $\mathrm{NH}^{3+}$ displays its characteristic bending modes at 1444.70 and $1408.31 \mathrm{~cm}^{-1}$. The strong absorption in the range $1100.92-$ $906.17 \mathrm{~cm}^{-1}$ is evidently due to the

phosphate part of the molecule. The peaks observed at 545.37 and $439.99 \mathrm{~cm}^{-1}$ is due to $\mathrm{NH}^{3+}$ oscillation ${ }^{[22]}$.

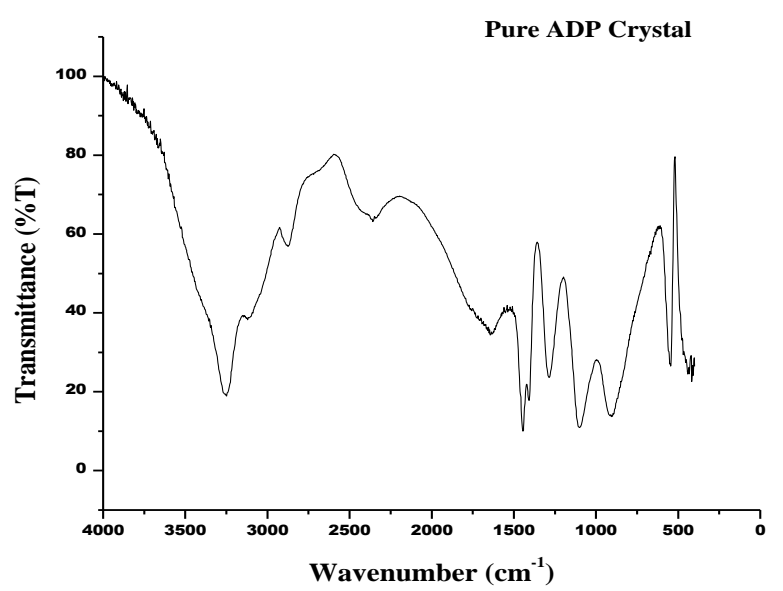

Fig 2: FTIR spectra of Pure ADP Crystal.

Table. 2: Characteristic Absorption Frequencies of Various Functional Groups

\begin{tabular}{rlll}
\hline S.No & Frequency Range & Intensity & Bond Assignments \\
\hline $\mathbf{1}$ & 3249 & $\mathrm{~s}$ & $\mathrm{O}-\mathrm{H}$ Stretching \\
$\mathbf{2}$ & 2874 & $\mathrm{~s}$ & Combination bond of Vibration \\
$\mathbf{3}$ & 1642 & $\mathrm{w}$ & Bond Vibration of water \\
$\mathbf{4}$ & $1444-1408$ & $\mathrm{~s}$ & Bond vibration of $\mathrm{NH}_{2}$ \\
$\mathbf{5}$ & $1100-906$ & $\mathrm{~s}$ & $\mathrm{P}-\mathrm{O}-\mathrm{H}$ Vibration \\
$\mathbf{6}$ & $545-439$ & $\mathrm{~s}$ & $\mathrm{PO}_{4}$ Vibration \\
\hline
\end{tabular}

\begin{tabular}{|c|r|r|r|l|l|l|}
\hline Crystal & $\mathrm{a}\left(\mathrm{A}^{\circ}\right)$ & $\mathrm{b}\left(\mathrm{A}^{\circ}\right)$ & $\mathrm{c}\left(\mathrm{A}^{\circ}\right)$ & Volume $\left(\mathrm{A}^{3}\right)$ & $\alpha=\beta=\gamma$ & System \\
\hline $\begin{array}{c}\text { Ammonium } \\
\text { dihydrogen } \\
\text { Phosphate } \\
(\mathrm{ADP})\end{array}$ & 7.5006 & 7.5006 & 7.5490 & 425.8 & 90 \% & Tetragonal \\
\hline
\end{tabular}




\subsection{Scanning Electron Microscope Analysis:}
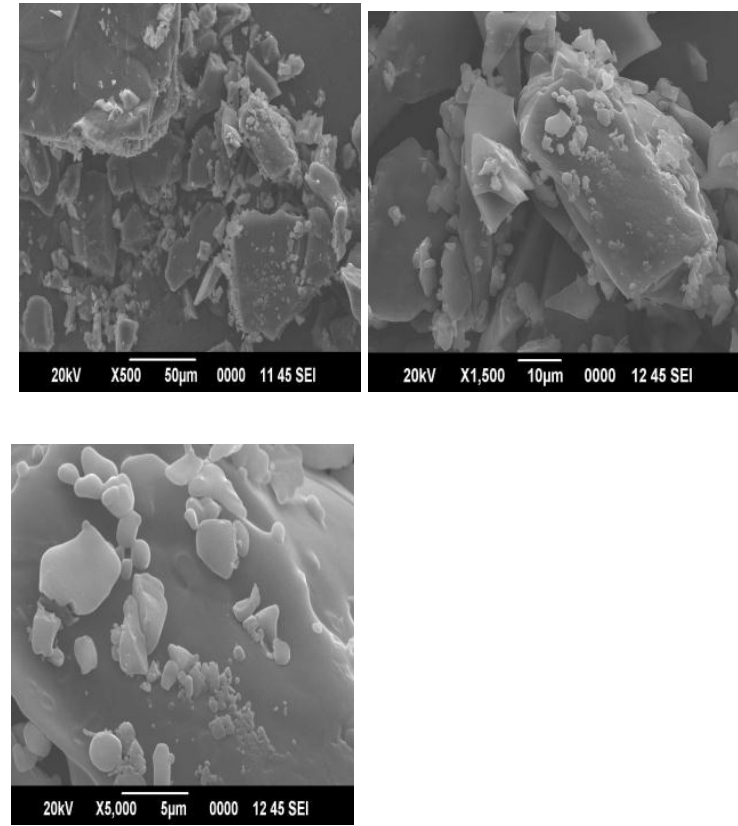

Fig.3: The SEM Images of Pure ADP Crystal.

Scanning electron microscopy (SEM) was performed using the J EOL Model JSM - 6390LV device (STIC, Cochin). SEM images showed the changes in the morphology of ADP crystals. Fig. 3 showed that the ADP crystals formed without influence of any additive are elongated tetragonal with an average size of $50.0 \times 5.0 \mu \mathrm{m}$. The Figure displays the crystals at a higher magnification, showing that the surfaces of most crystals are rough. Various types of separation occur in brittle and tough material. In the case of transgranular brittle fracture, crystallites are split with deformation. If the material is tough, sliding processes occur in crystallographically preferred planes; microvoids and cavities form themselves. The cavities widen, any metal remaining in between propagates and narrow edges are formed.

\subsection{Thermo Gravimetric Analysis(TGA) :}

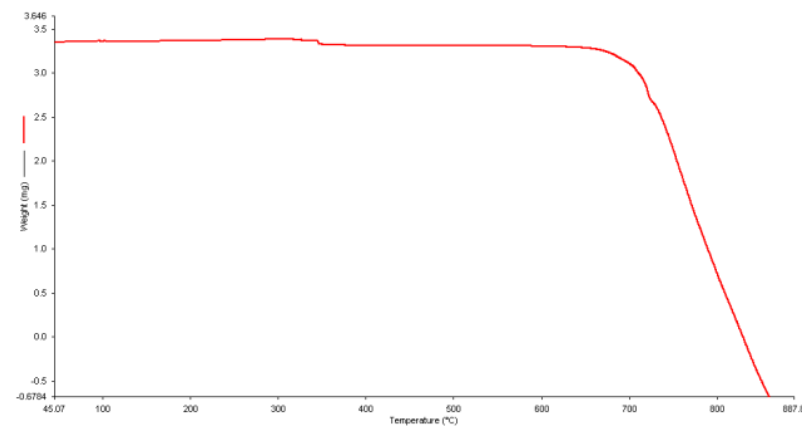

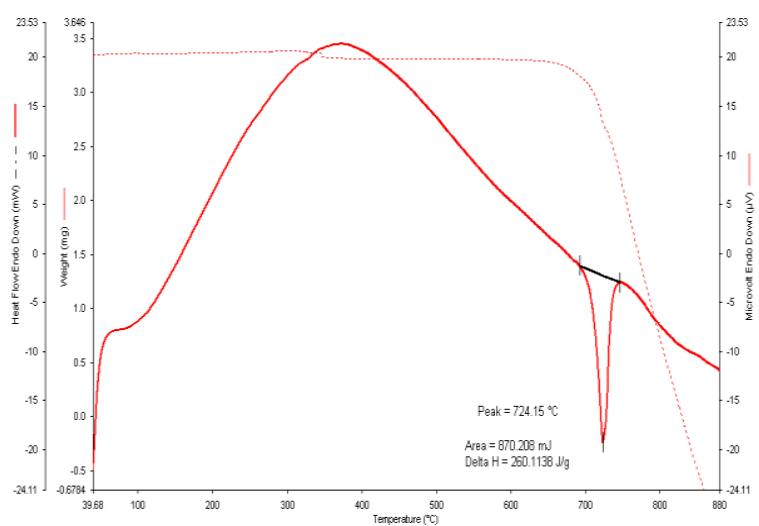

Fig 4: The TGA curve of Pure ADP Crystal.

Thermo gravimetric and differential thermal analyses give information regarding phase transition, water of crystallization and different stages of decomposition of the crystal system. The thermo gravimetric analysis of MAP single crystal was carried out between $30{ }^{\circ} \mathrm{C}$ and $300{ }^{\circ} \mathrm{C}$ in the nitrogen atmosphere at a heating rate of $20^{\circ} \mathrm{C} \mathrm{min}{ }^{-1}$ using Perkin Elmer, Diamond TG/DTA analyzer. The thermo gram and the differential thermo gravimetric trace of USA are shown in Fig.4. In TGA, there is no weight loss up to $\sim 682 \mathrm{C}$. This indicates that there is no inclusion of water in the crystal lattice, which was used as the solvent for crystallization. It is seen that the major weight loss starts at $700 \square \mathrm{C}$ and it continues up to $1020 \square \mathrm{C}$. The nature of weight loss indicates the decomposition point of the material. However, above this temperature, no weight loss has been observed. In the DTA, the strong endothermic peaks located $\sim 724 \square \mathrm{C}$ depict the crystallization of some of the phases of the decomposed material.

\section{CONCLUSIONS}

Good quality transparent single crystals of ammonium dihydrogen phosphate (ADP) $\left(\mathrm{NH}_{4} \mathrm{H}_{2} \mathrm{PO}_{4}\right)$ have been grown in slow evaporation technique at room temperature.The $\mathrm{X}$-ray diffraction pattern of ADP showed that the crystals possess tetragonal structure with lattice parameters in good agreement with the reported data (JCPDS Card No. 850815). The functional groups of ADP crystals were identified using FTIR. SEM reveals that the external morphology of ADP is just like various types of separation occur in brittle and tough material. In the case of transgranular brittle fracture, crystallites split are identified in the SEM images of ADP crystal.The thermogravimetric curve obtained for ADP, there is no weight loss up to $\sim 682 \mathrm{C}$. This indicates that there is no inclusion of water in the crystal lattice, which was used as the solvent for crystallization.

\section{REFERENCES}

[1] N. Zaitseva, L. Carman, Prog. Cryst. Growth Charact. 43,1 (2001).

[2] L. Glasser, Chem. Rev. 75,21 (1975).

[3] M.J. Gunning, R.E. Raab, W. Kucharczyk, J. Opt. Soc. Am. B18,1092 (2001) .

[4] E. Rushton, Br. J. Appl. Phys. 12.417 (1961).

[5] N. Peres, A. Boukhris, M. Souhassou, G. Gavoille, C. Lecomte, Acta Cryst. A55,1038 (1999). 
[6] R. Ledzion, K. Bondarczuk, W. Kucharczyk, Cryst. Res. Technol. 39, 161 (2004)

[7] Glass, A.M. and M.E. Lines, Principles and Applications of Ferroelectric and Related Materials, Oxford University Press, Oxford, pp 293, (1977).

[8] Courtens.E, Growth of Rubidium doped strain free and mixed crystals of ADP. Helv. Phys. Acta., 56:705 (1983).

[9] Ermerl, D. Electro optics, linear and nonlinear optical properties of KDP and its isomorphs, Ferroelectrics. Ferroelectrics, 72:95 (1987).

[10] Zaitseva, N.P., L.N.Rashkovich and S.V. Bogatyreva, Suability of $\mathrm{KH}_{2} \mathrm{PO}_{4}$ and $\mathrm{K}(\mathrm{H}, \mathrm{D})_{2} \mathrm{PO}_{4}$ solution at fast crystal growth rate. J. Crystal growth, 148: 276, (1995).

[11] Dmitriev, V.G., G.G.Gurzadyan and D.N. Nikogosyan, Hand book of nonlinear optical crystal, Springer verlag, Berlin, Heidelberg, pp : 14 - 35, (1991).

[12] A. Jayarama , S.M. Dharmaprakash, "Structural distortion in thiourea-mixed ADP crystals" Applied Surface Science 253, 944-949 (2006).

[13] A. Claude, V.Vaithianathan, R. Barivava Ganesh, R. Sathiyalakshmi and P.Ramasamy,"Growth and Characterization of Novel $\left(\mathrm{Ni}^{3+}, \mathrm{Mg}^{2+}\right.$ ) Bimetallic crystals of Ammonium dihydrogen Phosphate" Journal of Applied Sciences 6 (1): 85 - 89, (2006).

[14] A. Abdel-Kader, J. Mater. Sci. - Mater. Electron. 2, 7 (1991).

[15] N. Pe'ere`sy,M. Souhassouyx, B.Wynckey, G. Avoilleyx, A. Coussonzand, J. Phys: Condens. Matter 9, 6555 (1997).

[16] [16] R. Reintjes, E.C. Eckardt, Appl. Phys. Lett. 30, 91 (1977)
[17] R.J. Davey, J.W. Mullin, J. Cryst. Growth 26,45 (1974).

[18] R.I. Ristic, J.N. Sherwood, J. Phys. D: Appl. Phys. 24 , 171 (1991)

[19] J. Fontcuberta, R. Rodriguez, J. Tejada, J. Cryst. Growth 44,593 (1978).

[20] A. Boujhris, M. Souhassou, C. Lecomte, B. Wyneke, A Thalal, J. Phys: Condens. Matter 10, 1621 (1998).

[21] C.N. Banwell, E.M. McCash, Fundamentals of Molecular Spectroscopy, fourth ed., McGraw-Hill, NewYork, (1994).

[22] T. Balu , T.R. Rajasekaran, P. Murugakoothan, "Studies on the growth, structural, optical and mechanical properties of ADP admixtured TGS crystals" Current Applied Physics 9 435-440 (2009).

[23] G. G. Muley*, M. N. Rodea, S. A. Waghuley, B. H. Pawar," Studies on L-arginine doped ADP crystals for NLO applications" Optoelectronics and advanced materials - rapid communications vol. 4, No. 1, 2010, p. $11-14(2010)$

[24] S.Meenakshisundaram,S.Parthiban,G.Madhurambal and S. C. Mojumdar" Effect of low and high concentrations of kcl dopant on ADP crystal properties"Journal of Thermal Analysis and Calorimetry, Vol. 96 1, 77-80 (2009).

[25] Zhong degao1, teng bing1, Romano a Rupp, Vu tao, Ng qingguo1,Zhao yanshuail \& huang wanxia, "Optical homogeneity of ADP crystals from rapid growth" Condensed Matter Physics Vol.55 No.4-5: 378-381, (2010) 